\title{
Controlled Converter AC/DC through Small Input and Output Current
}

\author{
K. Bhaskara ${ }^{a}$ E. Santhosh \\ ${ }^{a}$ Department of Electrical and Electronics Engineering, Vel Tech Rangarajan Dr. Sagunthala R\&D Institute of \\ Science and Technology, Avadi, Chennai, India. E-mail: bhaskark@ veltech.edu.in \\ ${ }^{b}$ Department of Electrical and Electronics Engineering, Vel Tech Rangarajan Dr. Sagunthala R\&D Institute of \\ Science and Technology, Avadi, Chennai, India. E-mail: santhoshedukulla16@gmail.com
}

Article History: Received: 11 January 2021; Accepted: 27 February 2021; Published online: 5 April 2021

\begin{abstract}
A high controlled converter one form to another form of supply like (AC/DC) is displayed in this article. The system is planned converter become 2 shifted fundamental restricted Converter in this work-controlled method for boosting its knowledge power. In these, the present weight of the guideline switches in the presented converter can be diminished. What is more, the present influx of yield and contribution to it in like manner can be lessened. Additionally, every progression fundamental circuit is showed converter is operated four changes to give execution the capacity of voltage guideline and force factor (pf). Frequency modulation with secured on and off time intermissions are discard, now this converter. A $1 \mathrm{~kW}$ indicated the converter exists to see its display.
\end{abstract}

Keywords: Power Factor (pf) Frequency Modulation (FM) Alternating Current (AC), Direct Current (DC), Power Factor Correction (PFC).

\section{Introduction}

DC power flexibly is a blend of converter, critical unit outline work, Figure.1a indications the regular topography of DC power nimbly framework. This One utilizes the unrestrained branch close rectifier to perform the one form to another form like AC/ DC work in papers 1 and 2. In This topography is clear. Regardless, considering the way that the information current in this topography is not sine wave the situation sounds remain high the force factor of the geology is lesser. Utilizing the PFC circuit in DC power framework can increase this issue. The standard remote PFC circuit in which is created utilizing diodes, capacitor and inductor are utilized for power factor correction. In any situation, why it is worked at low reuse, it is having enormous and liberal and will limit its application run. The dynamic PFC circuit will be utilized to progress this issue. In this way, the disconnected DC power supply which make out of a working PFC circuit and a transformer separated DC to DC converter are the broadest topographies. Moreover, the most transformer-restricted DC to DC converter type is the full-interface type.

Figure. 1(b) is indicated the standard two-phase transformer-kept Converter.

The geography makes out of a working PFC circuit and a full-partner DC to DC converter. In the DCinterface capacitor gives decoupling among them. They will be just controlled, and they have exciting introductions. Regardless, they barge in with one another because they are non-simultaneously worked. Also, this geography has great conduction episodes since it joins a full-partner in the rectifier. Its controller is additionally continuously dazing, and its expense is high. 

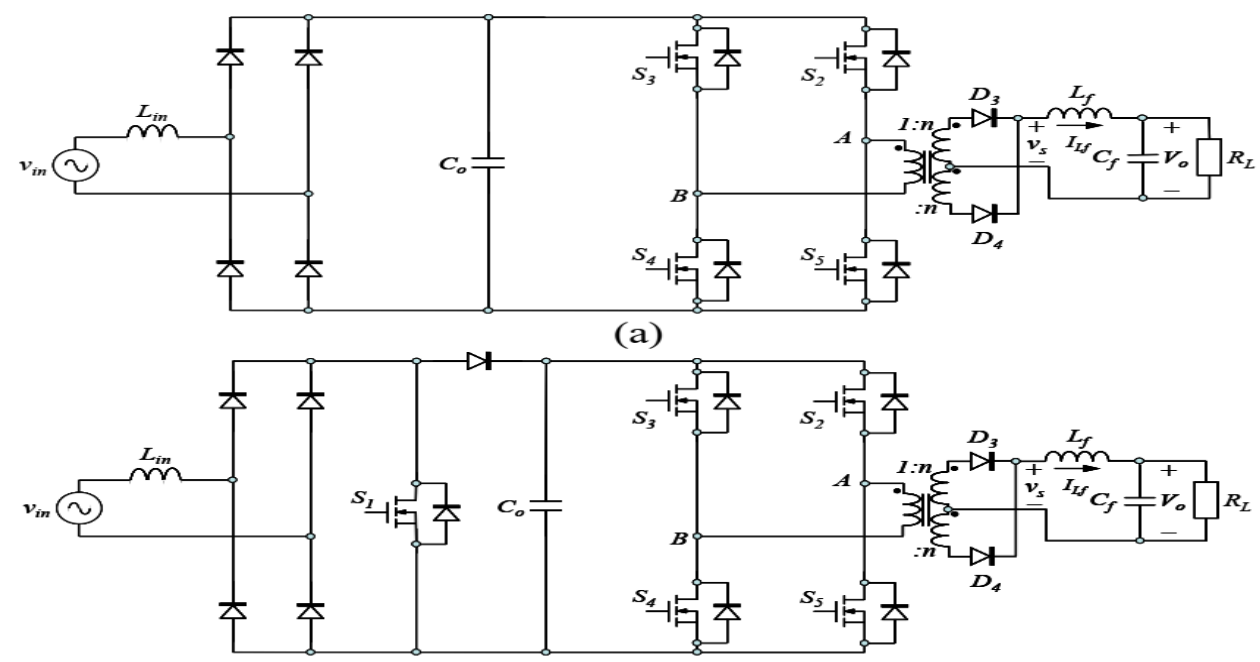

(b)

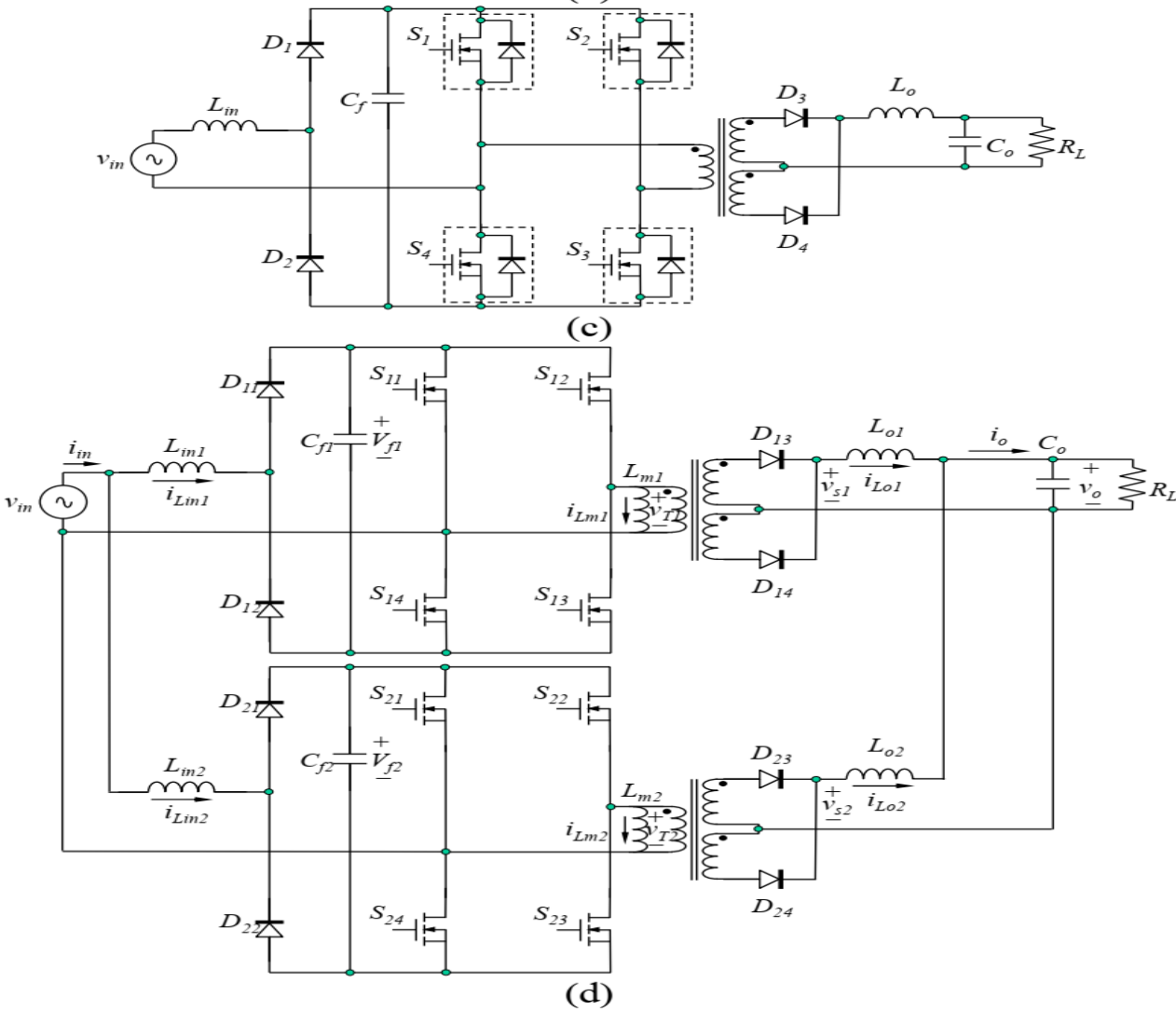

Figure 1. (a) The Geography for DC Power Flexibly. (b) Conventional 2 Phase transformer-detached Converter (c). The Introduced Single-stage Transformer-separated Converter. (d) The Introduced Interleaving Converter

For lessening the cost of the circuit, the multifaceted nature of the device, an elite one stage complete expansion Converter is presented and appeared in Figure. 1(c). The circuit construction just utilizes tetrad dynamic force changes toward play out the elements of intensity factor adjustment and voltage guideline. In this way, its expense is smaller than the others. For expanding appraised yield power, 2 indistinguishable maximum extension Converter is associated in parallel. They exist to share the appraised yield power, the present concern of intensity semiconductors in them could be diminished. Their supervision pulse width modulation (PWM) signs are the equivalent however $180^{\circ}$ stage move between them. Also, they are worked in a novel control methodology. In this way, the info and yield current wave in the exhibited converter can be diminished. Framework examination for foreseeing and assessing the introduced interleaving Converter execution is directed. 


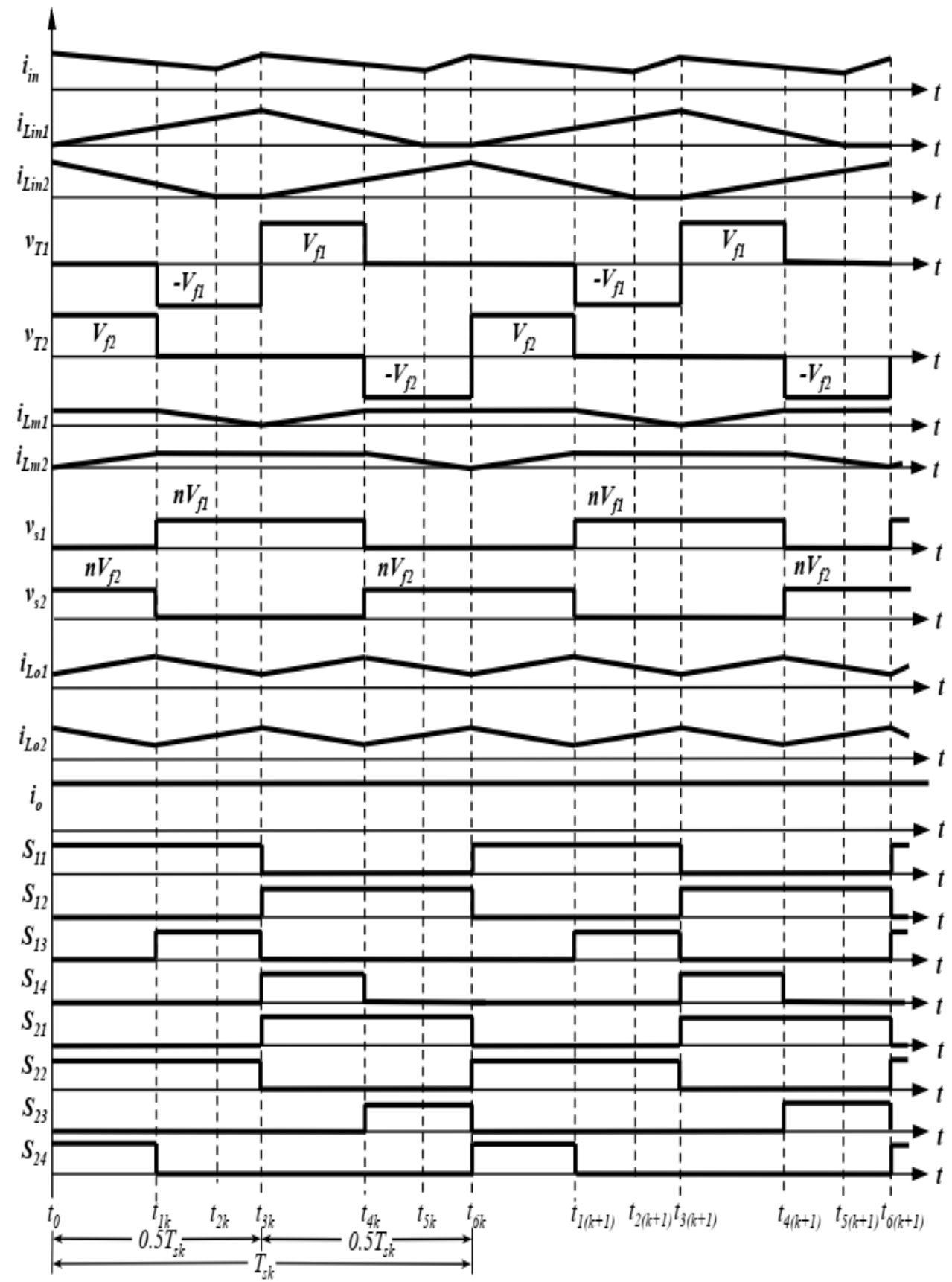

Figure 2. The Comparative Waveforms of the Presented Enclosing Converter

\section{Working Principle}

Figure. 1(d) shows the fundamental force circuit construction of the demonstrated most excellent interleaving Converter. The shown interleaving Converter makes out of two indistinct full increase Converters which are connected in comparing with $180^{\circ}$ stage move. Each full development Converter, in this projected topography will be isolated in two areas like the PWM intermittent transmission mode (DCM) step-up power factor corrector and the PWM full expansion DC to DC converter. The constraint of intensity factor corrector is moulding the data present to actuate the force factor, changing over the constrained air framework voltage to dc voltage. The PWM full development DC to DC converter plays out the restriction of withdrawal and DC to DC rule to follow the reference voltage. The information inductors Lin 1 and Lin2 give voltage support work, and the yield channel is made of Lo1, Lo2 and Co. The yield channel can channel the undesired voltage wave to get a reliable DC voltage. Cf1 and Cf2 remain the coupling capacitors among the info PFC level and yield DC to DC coordinate and they have the parts of supplying DC voltage and channel, and they should have the restriction of suffering advanced voltage weight since the front-end power factor corrector gives up the development voltage work. 

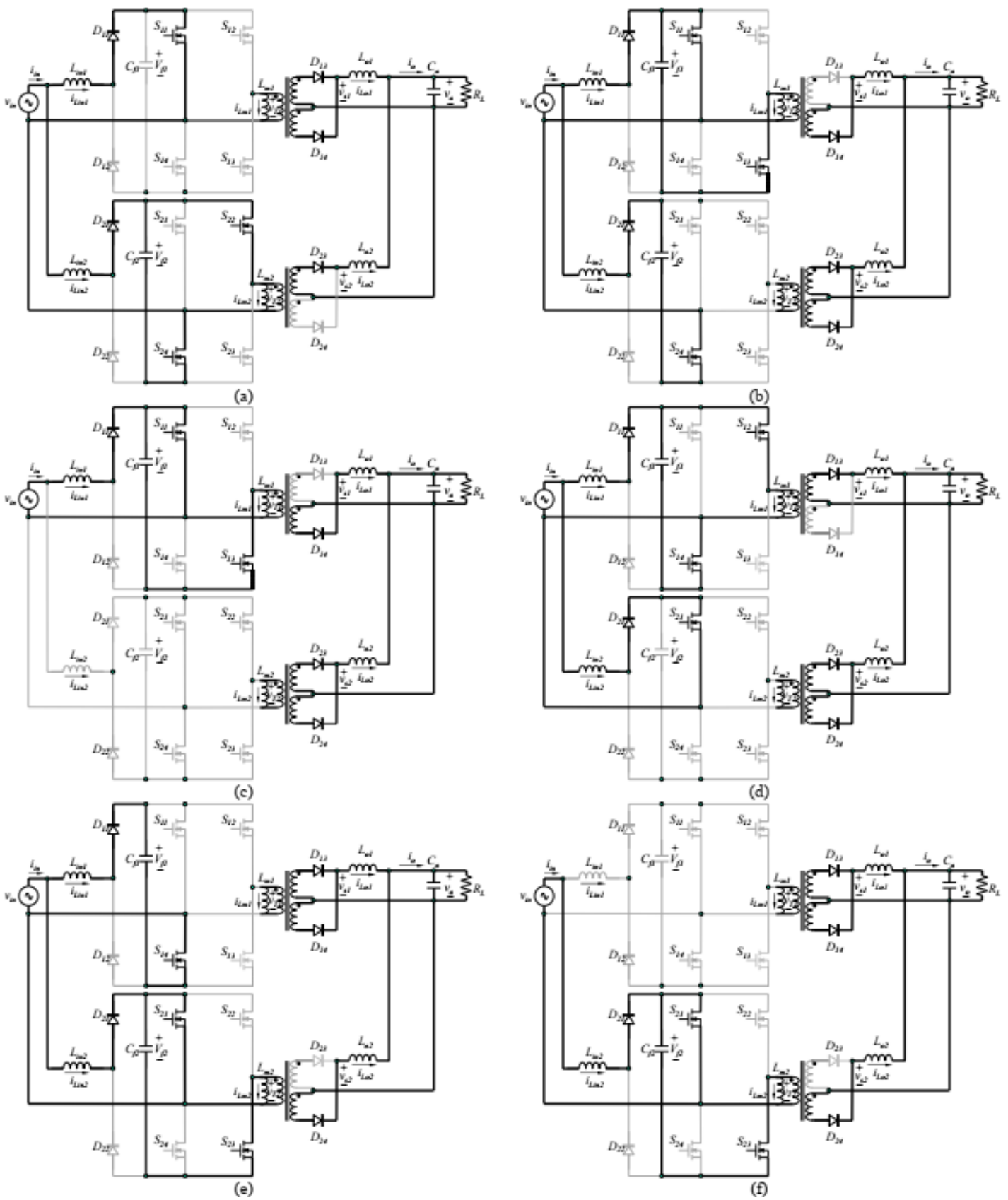

Figure 3. The Identical Circuit's Activity of the Current Interleaving Converter

In the proposed structure, the circuit tasks in a positive and negative half example of the line input voltage are comparable. The activity outline just reviews the activity delineation for the positive half cycle for improving the appraisal portrayal. Also, the demonstrated converter has been worked at a consistent state. Lin1, Lin1, Lo1, Lo2, Cf1, Cf2, and Co are flawless gadgets and the calamities in them can be ignored. Figure. 2 shows the development relative waveforms of the introduced interleaving Converter. In extra, the development proportional circuits of the shown interleaving Converter have in like way appeared in Figure. 3. The circuit development portrayal about the introduced interleaving Converter is appeared in following.

Level I: Previously, this Level, for the upper full-bridge Converter, $S_{11}, S_{12}, S_{13}$, and $S_{14}$ is a off in position. The DC to DC transformation phase of the high full-bridge Converter works at easygoing Level. Co is charged by iLo1. iLo1 likewise supplies the yield load. In this manner, iLo1 diminishes. For the lower full extension Converter, S21 and S23 are a turn-on and S22 and S24 is a turn-off. vin charges Lin2 through S21 and D21. Lm2 is demagnetized by Vf2. Vf2 likewise supplies the yield port using D24. Along these lines, iLo2 increments. In this Level, for the upper full extension Converter, S11 is turned on. vin charges Lin1 using S11 and D11. The DC to DC change phase of the upper full-bridge Converter persistently works at freewheeling state. iLo1 constantly diminishes. For the lower full extension Converter, S21 and S23 are turned on. S22 and S24 are killed. Cf2 is 
charged by iLin2 through D21 and S24. Lm2 is charged by Vf2. Vf2 likewise supplies the yield port using D23. In this manner, iLo2 constantly increments.

Level II: When $S_{13}$ is on in higher converter and $S_{22}$ is slain in the lesser converter, in this Level starts. Vin persistently charges Lin1 using S11 and D11. Lm1 is demagnetized by Vf1. Vf1 likewise supplies the yield port using D14. In this way, iLo1 increments. Cf2 is charged by iLin2 using D21 and S24. The DC to DC transformation phase of the lower full extension Converter works at freewheeling state. iLo2 diminishes.

Level III: During this Level, the higher converter works in the past state. vin consistently charges Lin1 using S11 and D11. Lm1 is consistently demagnetized by Vf1. Vf1 likewise constantly supplies the yield port using D14. Consequently, iLo1 consistently increments. For the lower converter, S24 is killed. The DC to DC transformation phase of the lower full extension Converter keeps up at freewheeling state. iLo 2 persistently diminishes.

Level IV: Through this Level, in the higher converter, S11 and S13 exist killed. S12 and S14 are turned on. Cf1 is charged by iLin1 through D11 and S14. Lm1 is charged by Vf1. Vf1 likewise supplies the yield port through D13. Along these lines, iLo1 ceaselessly increments. For the lesser converter, S21 is on. $v_{\text {in }}$ charges Lin2 using S21 and D21. The DC to DC transformation phase of the lesser full scaffold Converter persistently works at freewheeling state. iLo2 constantly diminishes.

Level V: This Level starts when S12 is killed in the upper converter and S23 is turned on in lesser converter. Cf1 is persistently charged by iLin1 using D11 and S14. The back DC to DC change phase of the upper full extension Converter works at freewheeling state. iLo1 diminishes. Vin charges Lin2 using S21 and D21. Lm2 is demagnetized by Vf2. Vf2 additionally supplies the yield port through D24. In this way, iLo2 increments.

Level VI: In this Level, the lower converter works in the past state. vin charges Lin2 using S21 and D21. Lm2 is ceaselessly demagnetized by Vf2. Vf2 likewise consistently supplies the yield port using D24. Accordingly, iLo2 ceaselessly increments. In the upper converter, S14 is killed. vin charges Lin2 through S21 and D21. The back DC to DC transformation phase of the upper full extension Converter keeps up at freewheeling state. iLo1 consistently diminishes.

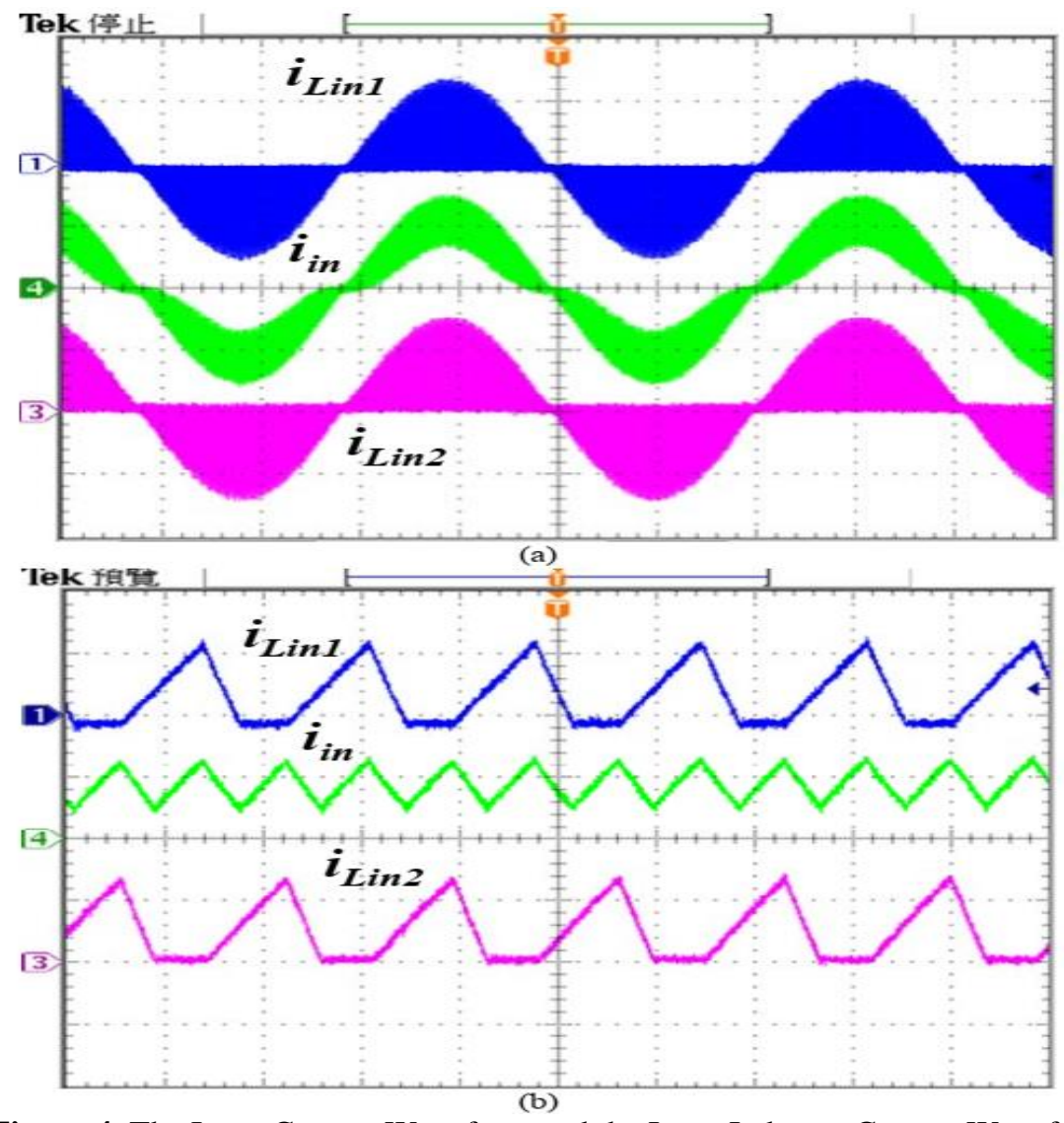

Figure 4. The Input Current Waveform and the Input Inductor Current Waveform 
For seeing the concert of the presented enclosing Converter, the explanation of its strategy and understanding is shown in following. Its conditions are:
A. AC input voltage $\left(\mathrm{v}_{\text {in }}\right): 110 \mathrm{Vrms}$
B. DC O/P Voltage: $50 \mathrm{~V}$
C. Rated maximum power output: $1 \mathrm{~kW}$
D. Commutation frequency $\left(\mathrm{f}_{\mathrm{c}}\right): 100 \mathrm{kHz}$

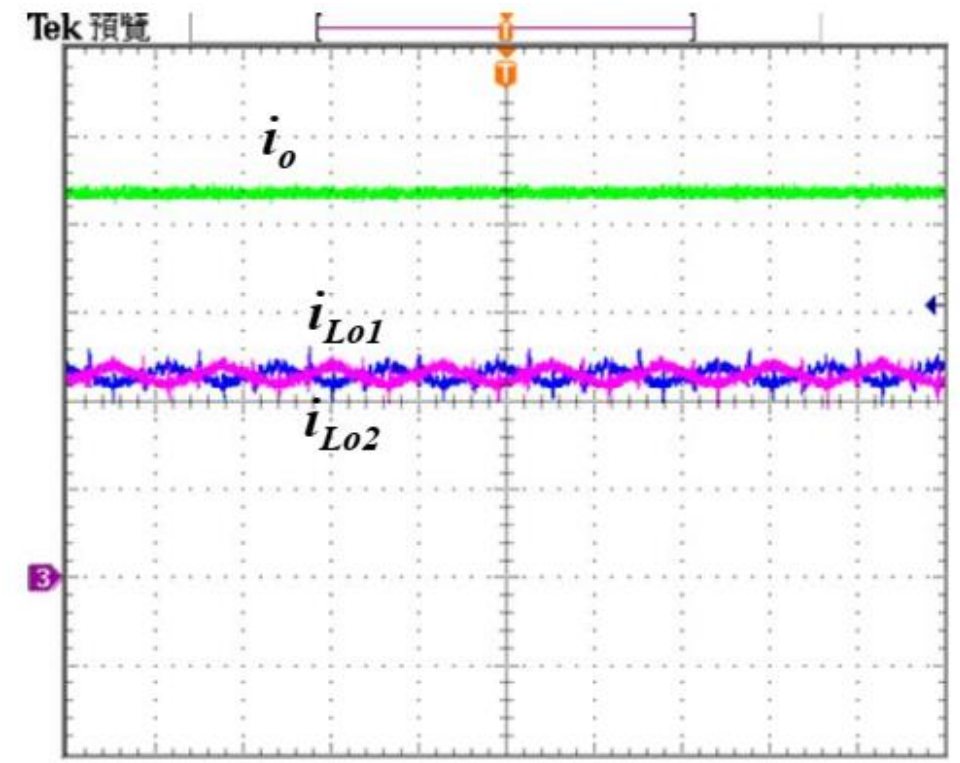

Figure 5. The Output Inductor Current Waveforms and the Output Current Waveform

The comparative apparatuses in the power main circuit shown in Figure. 1(d) can be considered as follow.

- The input to the inductors $\operatorname{Lin} 1=\operatorname{Lin} 2=100 \mu \mathrm{H}$

- The coupling capacitors $C f 1=C f 2=940 \mu \mathrm{F}$.

- The output filter inductors $L o 1=L o 2=1 \mathrm{mH}$.

- The filter capacitor output $C o=1 \mu \mathrm{F}$.

- The active power switches MOSFET's IRFP460.

- The power diodes are S30L60.

The input current $i_{i n}$, the inductor input flows iLin1 and iLin2, and the wave flows at evaluated yield power are controlled. Figure. 4(a) and Figure. 4(b) show the waveforms. Additionally, the io(output current) the inductor yield flows iLo1 and iLo2, and the wave flows at appraised yield power are likewise controlled. Figure. 5 show the waveforms. Distinguishing Figure. 4 and Figure. $5, i_{\text {in }}=i \operatorname{Lin} 1+i L i n 2$ and io=iLo1+iLo2. Additionally, iLin1 is near iLin2 and iLo1 is near iLo2. The current encasing exchanging current (AC) to Direct current (DC) converter has a current circulation trademark. The iLin1 and iLin2 are ended current waveforms. Be that as it may, the $i_{\text {in }}$ is staying current waveform. Along these lines, the info current(IP) music are concentrated, and the force factor is additionally dynamic. Further, the wave-current of io is minor. The introduced encasing rotating current (AC) to Direct current (DC) converter has a decent expelling swell current trademark under the novel control procedure.

\section{Conclusion}

A casing AC to DC converter with raised introduction trademark is introduced. The force principle circuit is basic. Likewise, the current converter utilizes the traditional Pulse width balance control technique to frame the current waveform which is a nearby air conditioning waveform and change the yield voltage. The introduced converter has the highlights of raised force factor, lower swell current yield, and moral current sharing trademark. In this way, the introduced converter has a low circuit cost. The clarification of the circuit procedure and plan strategy has appeared.

\section{References}

4. Redl, R., \& Sokal, N.O. (1980). Push-pull current-fed multiple-output DC/DC power converter with 
only one inductor and with 0 to $100 \%$ switch duty ratio. In IEEE Power Electronics Specialists Conference, 341-345.

5. Clark, P.W. (1976). Converter regulation by controlled conduction overlap. U.S. Patent 393824 , Assigned to Bell Telephone Laboratories, Inc., Murray Hill, NJ 07974.

6. Fey, M. A switch mode power supply, In IEEE International Communications Energy Conference. Rec., Intelec 82, pp. 277-284.

7. Schlecht, M.F. (1983). Novel topological alternatives to the design of a harmonic-free, utility/dc interface. In IEEE Power Electronics Specialists Conference, 206-216.

8. Latos, T.S., \& Bosack, D.J. (1982). A high efficiency $3 \mathrm{~kW}$ switch mode battery charger. In IEEE Power Electronics Specialists conference, 341-349.

9. Chambers, D. (1983). A new high frequency resonant technique for dynamic correction of off-line converter input current waveforms. In Proc. Powercon, 10, 1-7.

10. Keller, R., \& Baker, G. (1984). Unity power factor off line switching power supplies. In INTELEC'84International Telecommunications Energy Conference, 332-339.

11. Manias, S. (1985). An converter with improved input power factor and high-power density. In Industrial Electronics Conf. Rec., 